\title{
Incidence and pattern of tuberculosis treatment success rates in different levels of the human development index: a global perspective
}

\author{
Salman Khazaeia, Shahab Rezaeian ${ }^{\text {b* }}$ (D), Vali Baigic (D), Mohammad Saatchic, Leila Molaeipoor ${ }^{\mathrm{d}}$, Zaher Khazaeie, Somayeh Khazaeif \\ and Owais Razac (iD)
}

\author{
${ }^{a}$ Department of Epidemiology, School of Public Health, Hamadan University of Medical Sciences, Hamadan, Iran \\ ${ }^{b}$ Research Center for Environmental Determinants of Health (RCEDH), Kermanshah University of Medical Sciences, Kermanshah, Iran \\ 'Department of Epidemiology and Biostatistics, School of Public Health, Tehran University of Medical Sciences, Tehran, Iran \\ ${ }^{d}$ Department of Epidemiology, Pasteur Institute of Iran, Tehran, Iran \\ eSocial Determinants of Health Research Center, Kurdistan University of Medical Sciences, Sanandaj, Iran \\ ${ }^{f}$ Faculty of Paramedical Science, Department of Operating Room, Hamadan University of Medical Sciences, Hamadan, Iran \\ *Corresponding author, email: shahab.rezayan@gmail.com
}

Background: Tuberculosis (TB) treatment success rate remains a public health challenge in many developed and developing countries. The correlation between the incidence and pattern of TB and the Human Development Index (HDI) has not been globally determined. This study aimed to determine the correlation between incidence and pattern of TB treatment success rates and HDI around the world.

Methods: In this global perspective, we used data on incidence and treatment success rates of TB and HDI from the World Health Organisation (WHO) and World Bank, respectively.

Results: The highest estimated incidence and lower treatment success rates of TB were restricted to countries with low HDIs. Life expectancy, education level, gross national income, $\mathrm{HDI}$, and urbanisation were significantly associated with both TB incidence and treatment success rates.

Conclusion: Patterns in TB incidence and treatment success rates are correlated with Human Development Indices. In addition to following WHO strategies, policy makers need to focus on the social and environmental determinants in order to reduce the TB burden, particularly in low income countries.

Keywords: ecological study, human development index, incidence, tuberculosis

\section{Introduction}

Tuberculosis (TB) is still considered one of the major global threats to public health, despite promised targets of the Millennium Development Goals (MDGs). In 2014, about 9.6 million people were affected and 1.5 million people died due to this disease worldwide. ${ }^{1}$ TB occurs in all regions; however, about $80 \%$ of new cases occur in 22 countries including India, Indonesia, Nigeria and Pakistan. In addition, in 2014, about 480000 people around the world were diagnosed with multidrug-resistant TB (MDR-TB) among which more than half occurred in India alone. ${ }^{2}$ The World Health Organisation (WHO) updated their TB program and now aims to completely eliminate TB by 2050. TB elimination means that the number of active smear-positive cases is less than one per one million people per year. ${ }^{3}$ Achieving this goal requires a reduction in incidences of the disease of up to $16 \%$ per year, whereas the current reduction in incidence of TB is only $1 \%$ per year. ${ }^{4}$

About one third of the world's population is infected with a latent TB infection, and $10 \%$ of people may be infected with TB during their lifetime. ${ }^{2}$ Co-infection with HIV, and the consequential weakening immune system, has become the most important risk factor known in recent years to activate latent mycobacterium TB infection. ${ }^{5}$ The role of other risk factors such as diabetes mellitus, smoking, alcohol, malnutrition and silicosis have also been known to affect TB. ${ }^{6-11}$ Also, exposure to the conditions associated with poverty, such as overcrowding, houses with poor ventilation, poor socio-economic status, homelessness, immigration, and being in a minority (in the less developed countries) or marginalised citizens (in developed countries) facilitate TB contraction. ${ }^{8,12-14}$ The afore-mentioned factors are considered fundamental challenges in controlling TB.

The Human Development Index (HDI), which is a composite statistic of life expectancy, education, and per capita income, was introduced as a new indicator for comparing the human development of countries in 1990. This indicator is used to determine the relationship between social and economic development of countries, and incidence rate of diseases. This study aimed to determine the incidence and pattern of treatment success rate of TB in terms of different levels of $\mathrm{HDI}$ around the world.

\section{Materials and methods}

This is a global ecologic study to analyse the relationship of the age-specific incidence and treatment success rate (TSR) of TB, with the HDI. HDI has several main components such as: life expectancy at birth (LEB); mean years of schooling (MYS); and, gross national income (GNI) per capita. Some ancillary indices of $\mathrm{HDI}$ include: percentage of urbanisation, and percentage of childhood stunting. Data for 184 countries on incidence and TSR of TB for the year 2012 were obtained from WHO reports; and, data on the HDI and other indices were obtained from the World Bank Report 2013 available at http://databank.worldbank.org/ data/reports.aspx.

Inclusion for analysis was restricted to countries for which the epidemiologic data from the World Bank were available. In this study, we used the correlation bivariate method for assessment 


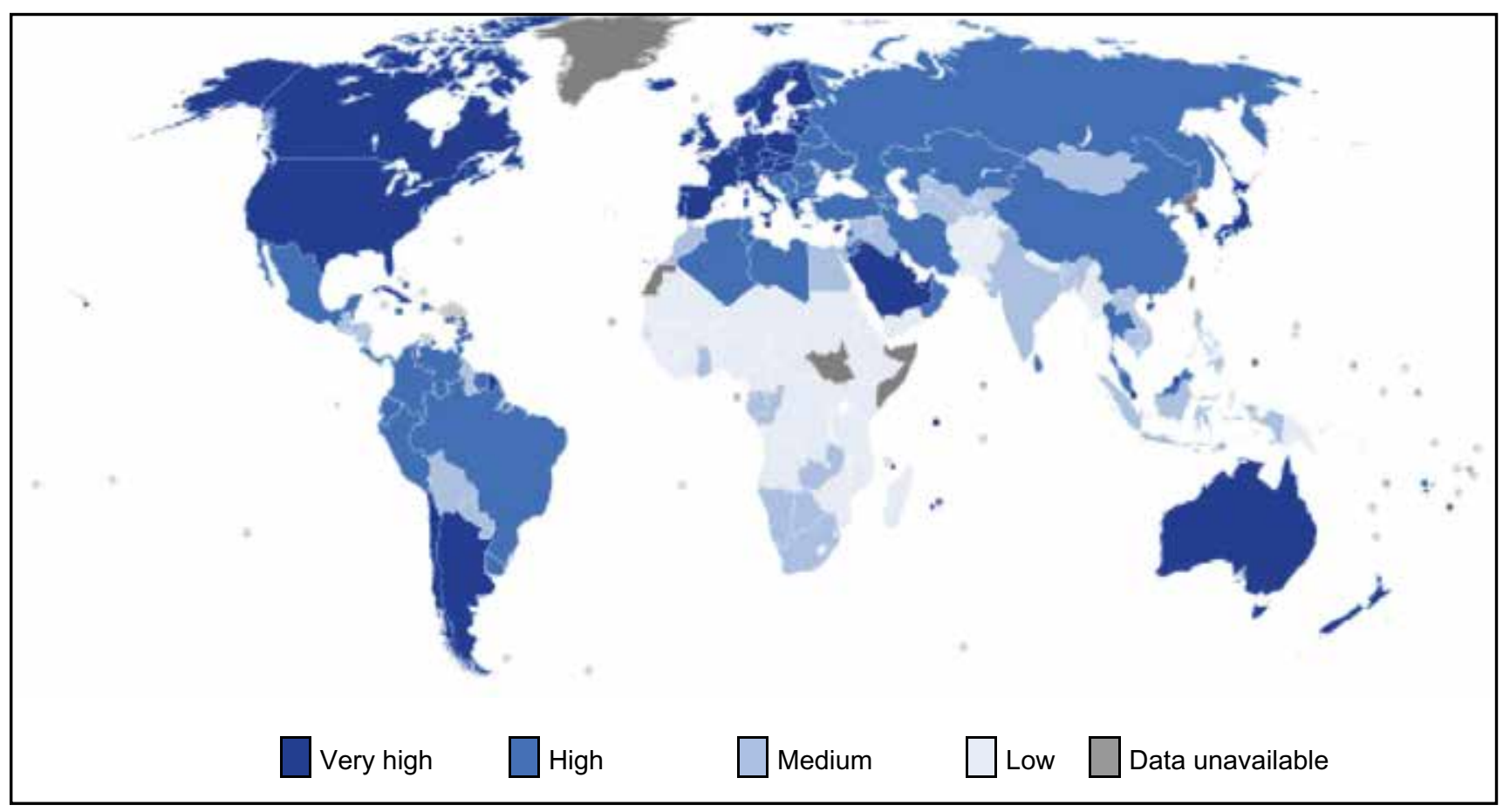

Figure 1: World map indicating the categories of Human Development Index by country (based on 2013 data).

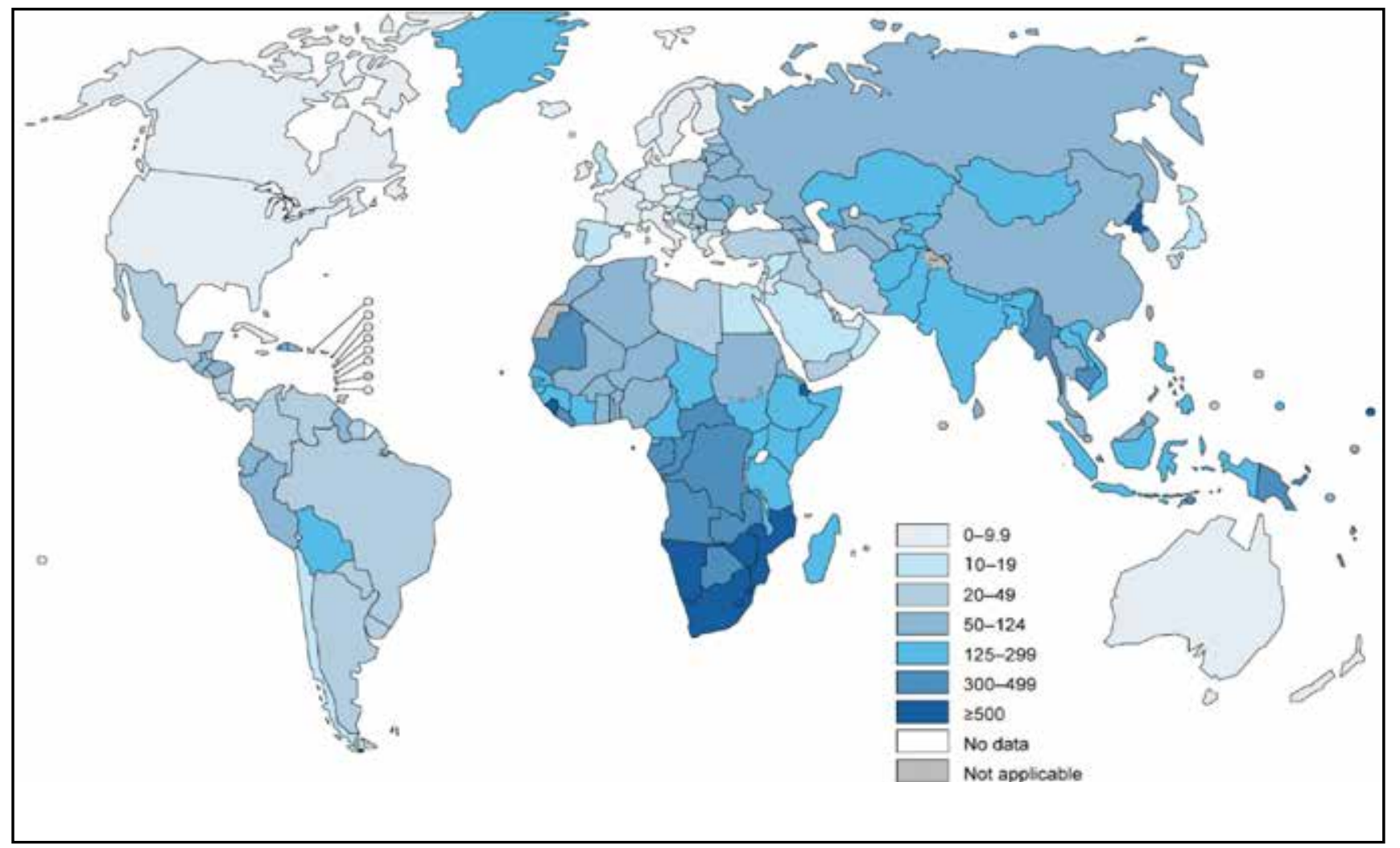

Figure 2: World map indicating the estimated TB incidence by country (based on 2013 data, Data source: Global Tuberculosis Report 2013, WHO).

of the correlation between the TB incidence rate and TSR with the HDl; we also used linear regression models for the assessment of effect of HDI on TB occurrence rates. Multiple linear regression models were ruled out due to extreme co-linearity of predictors. The level of significance was considered less than 0.05 for twosided statistical tests. Data were analysed using Stata software version 12 (StataCorp, College Station, TX, USA).

\section{Results}

The results of this study showed that the highest HDI index values belonged to privileged countries such as USA, Canada, Australia, and Western Europe (Figure 1). In addition, Figure 2 shows the estimated TB incidence worldwide. Accordingly, TB incidence rates occurred most frequently in countries such as 
Table 1: Tuberculosis incidence, treatment success rate and HDI component by different HDI regions in 2012

\begin{tabular}{l|c|c|c|c|c|c|}
\hline \multirow{2}{*}{ Region } & \multicolumn{2}{|c|}{ TB Index } & \multicolumn{4}{c|}{ HDI component } \\
\cline { 2 - 7 } & EI & TSR & LEB & MYS & GNI & HDI \\
\hline $\begin{array}{l}\text { Very high } \\
\text { human } \\
\text { develop- } \\
\text { ment }\end{array}$ & 9.84 & 80.2 & 80.2 & 11.7 & 40,046 & 0.89 \\
\hline $\begin{array}{l}\text { High } \\
\text { human } \\
\text { develop- } \\
\text { ment }\end{array}$ & 20.65 & 81.97 & 74.5 & 8.1 & 13,231 & 0.74 \\
$\begin{array}{l}\text { Medium } \\
\text { human } \\
\text { develop- } \\
\text { ment }\end{array}$ & 133.8 & 70.65 & 67.9 & 5.5 & 5,960 & 0.61 \\
\hline $\begin{array}{l}\text { Low } \\
\text { human } \\
\text { develop- } \\
\text { ment }\end{array}$ & 237.1 & 76.82 & 59.4 & 4.2 & 2,904 & 0.49 \\
\hline $\begin{array}{l}\text { p-value } \\
\text { (F-test) }\end{array}$ & $<0.001$ & $<0.001$ & & & & \\
\hline
\end{tabular}

Notes: El: Estimated incidence (per 100,000 population), TSR: Treatment success rate (\%), HDI: Human development index, LEB: Life expectancy at birth, MYS: Mean years of schooling, GNI: Gross national income per capita, TB: Tuberculosis.

South Africa, Namibia, Zimbabwe, and Sierra Leone with a rate greater than 500 per 100000 persons.

More specifically, in high or very high developed regions the highest value of LEB, MYS, GNI, and total HDI was estimated to be $80.2,11.7,40$, and 0.89 , respectively (Table 1 ). In contrast, the greatest incidence rates of TB occurred in less developed countries, whereas the highest success rate in TB treatment (81.97\%) was achieved in countries with a high level of development.

According to Figure 3, global HDI has a negative correlation with both TB incidence $(R=-0.51, p<0.05)$ and treatment success rate (TSR) $(\mathrm{R}=-0.18, p=0.018)$.

Linear regression models showed that all components of HDI were significantly associated with TB incidence (Table 2). On average, a unit increase in life expectancy, year of schooling, GNI, urbanisation and $\mathrm{HDI}$ can significantly decrease TB incidence. The impact of predictors on the TSR, however, was slightly different, and only significant for GNI, HDI and percentage of urbanisation. It was observed that a unit increment in these predictors, results in decrement of TSR by $0.16,15.6$ and 0.16 , respectively. (a)

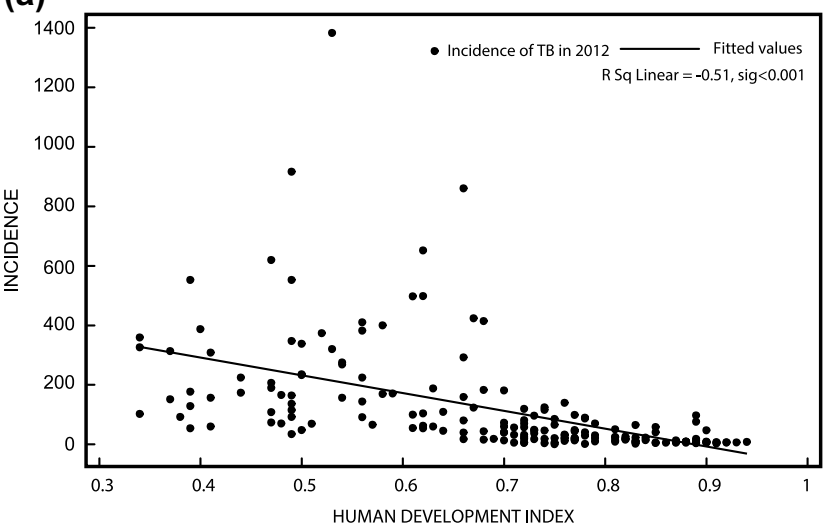

(b)

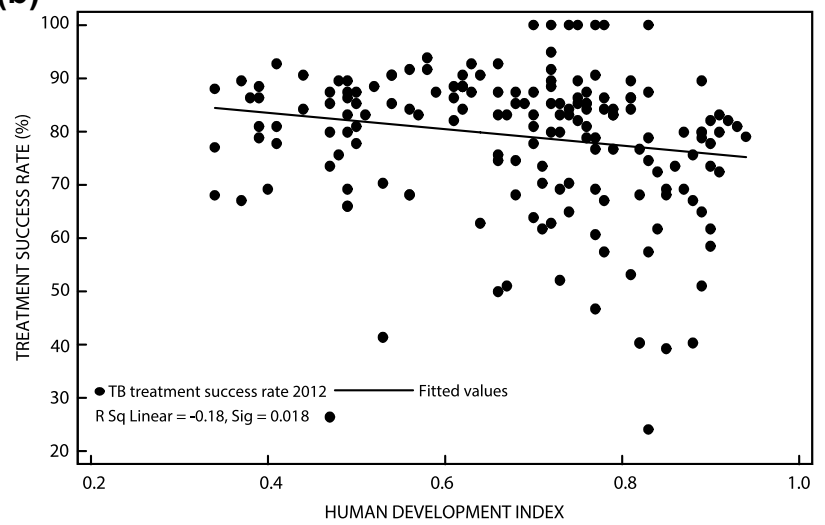

Figure 3: Correlation between the Human Development Index and TB incidence and treatment success rate in the world in 2012.

\section{Discussion}

Despite the importance and necessity of the directly observed treatment, short course (DOTS) strategy in reducing TB-related deaths, it seems that the national incidence rate of TB has a closer relationship with socio-economic factors such as the HDI. ${ }^{15}$ In the present study, we used data from 184 countries to assess correlations between incidence of TB and TSR with HDI, a commonly used socio-economic index. Results from this study show that there is a significant correlation between the incidence of TB and TSR with the HDI, such that countries with better HDI have lower incidences of TB and higher TSRs. Previous studies have also shown that one of the effective factors on incidence rate and incidence trend of TB is HDI. ${ }^{16,17}$ Previous research identifying trends in incidence of TB in 134 countries, and exploring the association between these trends and various indicators for development, found that $\mathrm{HDI}$ was inversely related to the incidence rate of TB. A similar finding from the Asia-Pacific region showed that socio-economic factors (such as $\mathrm{HDI}$ ) are an

Table 2: Effect of HDI components and demographic variables on TB incidence and treatment success rate by logistic regression

\begin{tabular}{|c|c|c|c|c|c|c|}
\hline \multirow[t]{2}{*}{ Variable } & \multicolumn{3}{|c|}{ TB Incidence } & \multicolumn{3}{|c|}{ Treatment success rate } \\
\hline & B & $95 \% \mathrm{Cl}$ & $p$-value & B & $95 \% \mathrm{Cl}$ & $p$-value \\
\hline Life expectancy at birth & -13.05 & $(-15.4,-1.7)$ & $<0.001$ & -0.14 & $(-0.36,0.09)$ & 0.230 \\
\hline Mean years of schooling & -22.4 & $(-31.7,-14.28)$ & $<0.001$ & -0.64 & $(-1.3,0.001)$ & 0.051 \\
\hline Gross national income per 1000 capita & -3.6 & $(-5,-2.17)$ & $<0.001$ & -0.16 & $(-0.27,-0.04)$ & 0.006 \\
\hline HDI & -597.2 & $(-746,-448)$ & $<0.001$ & -15.4 & $(-27.95,-2.9)$ & 0.016 \\
\hline Urbanisation (\%) & -2.68 & $(-3.75,-1.63)$ & $<0.001$ & -0.16 & $(-0.24,-0.08)$ & $<0.001$ \\
\hline Stunting in children* & 5.8 & $(3.24,8.37)$ & $<0.001$ & 0.13 & $(-0.02,0.23)$ & 0.085 \\
\hline
\end{tabular}

${ }^{*}$ Children stunting moderate or severe (\% under age 5), HDI: Human Development Index, TB: Tuberculosis, Cl: Confidence Interval. 
effective predictor of incidence and prevalence of TB..$^{18}$ Tuberculosis is a disease associated with poverty and factors, such as malnutrition, overcrowding and smoking, have a positive effect on increasing the incidence rate. ${ }^{19}$ Therefore, incidence rates of TB in developing countries are affected by social and economic determinants more so than proper implementation and success of the DOTS program. ${ }^{16}$

Results of the linear regression model showed that all three HDI markers affect incidence and success rates of TB treatment. Results of a previous study that was conducted using data from 165 countries showed that the incidence rate of TB has reduced to 8.7 cases per hundred thousand people with an increase in life expectancy per year, ${ }^{20}$ which is consistent with results from our study. Education can affect the incidence of disease and success rates of treatment through mechanisms such as promotion of healthy behaviors, adequate nutrition, ${ }^{21}$ and the early diagnosis and treatment of TB.2. Results of this study also show that TB incidence is associated with malnutrition. A previous study showed that malnutrition increases the susceptibility to infection and any delay in receiving therapeutic intervention can aggravate the infection. ${ }^{23}$

There is a significant correlation between the lack of success of TB treatment and increased patient age. Advanced age may be a contributing factor for the lack of success in TB treatment due to a higher life expectancy in countries with a high level of HDI compared to other countries with a lower HDI. ${ }^{24}$ Another is the high number of immigrants and refugees in these countries who may not have proper access to health services. ${ }^{24-26}$ Results from a study conducted in Europe showed that one of the reasons for the poor success rate of TB treatment in these countries is an uncertainty of outcome in the treatment of patients who are immigrants and from mobile populations in these countries, for whom there is no possibility of follow-up. ${ }^{27}$

Although urbanisation can increase the burden of TB through high population density and exposure to specific risk factors such as smoking and changes in lifestyle, ${ }^{28}$ our study shows that there is an inverse correlation between urbanisation and the incidence of this disease. This may result from the impact of uncontrolled and confounding variables in the study. However, urbanisation is one of the fundamental obstacles in the implementation of TB control strategies and can reduce the success of treatment due to the lack of proper access to health services and a lack of proper supervision, and subsequently improper patient compliance..$^{29}$

Some limitations and strengths should be noted in this study. We used data from the WHO and World Bank reports, which have consistent definitions and allowed us to compare standardised rates across several different regions and countries. This helped to minimise limitations associated with selection and information biases and sample size. Nevertheless, ecological fallacy plays an important role in ecological study with which one cannot produce inference about the nature of process affecting individuals using aggregated data. Another limitation in this global ecological study is the inability to fully control confounding factors.

\section{Conclusion}

Patterns in TB incidence and treatment success rates are correlated with Human Development Indices. In addition to following WHO strategies, policy-makers need to focus on social and environmental determinants to reduce the TB burden, particularly in low income countries.
Acknowledgements - The data from WHO and World Bank reports were used for this study. This research did not received any specific funding. The authors declare that they have no conflict of interests.

\section{ORCID}

Shahab Rezaeian (ID http://orcid.org/0000-0002-5094-5315

Vali Baigi (iD http://orcid.org/0000-0002-5094-5315

Owais Raza (D) http://orcid.org/0000-0002-3410-441X

\section{References}

1. World Health Organization. Global Tuberculosis Report 2015. Geneva: WHO; 2015 [updated Nov, 2015; cited Nov, 2015]. Available from: http://www.who.int/tb/publications/global_report/gtbr15_main_ text.pdf?ua $=1$

2. World Health Organization. Tuberculosis. Geneva: WHO; 2015 [updated Oct, 2015; cited Nov, 2015]. Available from: http://www. who.int/mediacentre/factsheets/fs104/en/.

3. Hopkins DR. Disease eradication. N Engl J Med. 2013;368(1):54-63.

4. Dye C, Glaziou P, Floyd K, et al. Prospects for tuberculosis elimination. Annu Rev Public Health. 2013;34:271-86.

5. Ministiry of Health. National Guide for Combating Tuberculosis [Persian]. Tehran: MOHME; 2010.

6. Baker MA, Harries $A D$, Jeon $C Y$, et al. The impact of diabetes on tuberculosis treatment outcomes: a systematic review. BMC Med. 2011;9(1):81.

7. Hall V, Thomsen RW, Henriksen $O$, et al. Diabetes in Sub Saharan Africa 1999-2011: epidemiology and public health implications. A systematic review. BMC Public Health. 2011;11(1):564.

8. Lonnroth $\mathrm{K}$, Williams BG, Cegielski $\mathrm{P}$, et al. A consistent log-linear relationship between tuberculosis incidence and body mass index. Int J Epidemiol. 2010;39(1):149-55.

9. Maurice J. WHO framework targets tuberculosis-diabetes link. Lancet 2011;378(9798):1209-10.

10. Rehm J, Samokhvalov AV, Neuman MG, et al. The association between alcohol use, alcohol use disorders and tuberculosis (TB). A systematic review. BMC Public Health. 2009;9(1):450.

11. van Zyl-Smit RN, Brunet $L, P a i M$, et al. The convergence of the global smoking, COPD, tuberculosis, HIV, and respiratory infection epidemics. Infect Dis Clin North Am. 2010;24(3):693-703.

12. Blouin C, Chopra M, van der Hoeven R. Trade and social determinants of health. Lancet. 2009;373(9662):502-7.

13. Lonnroth K, Castro KG, Chakaya JM, et al. Tuberculosis control and elimination 2010-50: cure, care, and social development. Lancet. 2010;375(9728):1814-29.

14. Raviglione M, Krech R. Tuberculosis: still a social disease. Int J Tuberc Lung Dis. 2011;15(Suppl 2):S6-8.

15. Hargreaves JR, Boccia D, Evans CA, et al. The social determinants of tuberculosis: from evidence to action. Am J Public Health 2011;101(4):654-62.

16. Dye $\mathrm{C}$, Lonnroth $\mathrm{K}$, Jaramillo $\mathrm{E}$, et al. Trends in tuberculosis incidence and their determinants in 134 countries. Bulletin of the World Health Organization. 2009;87(9):683-91.

17. Castañeda-Hernández DM, Tobón-García D, Rodríguez-Morales AJ. Association between tuberculosis incidence and the Human Development Index in 165 countries of the world. Rev Peru Med Exp Salud Publica. 2013;30(4):560-8.

18. Wu J, Dalal K. Tuberculosis in Asia and the pacific: the role of socioeconomic status and health system development. Int J Prev Med. 2012;3(1):8-16.

19. Schmidt CW. Linking TB and the environment: an overlooked mitigation strategy. Environ Health Perspect. 2008;116(11):A478-85.

20. Oxlade O, Schwartzman K, Behr MA, et al. Global tuberculosis trends: a reflection of changes in tuberculosis control or in population health? Int J Tuberc Lung Dis. 2009;13(10):1238-46.

21. Blas E, Kurup AS. Equity, social determinants and public health programmes. Geneva: World Health Organization; 2010.

22. Bassili A, Seita A, Baghdadi S, et al. Diagnostic and treatment delay in tuberculosis in 7 countries of the Eastern Mediterranean region. Infect Dis Clin Pract. 2008;16(1):23-35. 
23. Boccia D, Hargreaves J, Ayles $\mathrm{H}$, et al. Tuberculosis infection in Zambia: the association with relative wealth. Am J Trop Med Hyg. 2009;80(6):1004-11.

24. Karo B, Hauer B, Hollo V, et al. Tuberculosis treatment outcome in the European Union and European Economic Area: an analysis of surveillance data from 2002-2011. Euro Surveill. 2015;20(49):pii30087. doi: 10.2807/1560-7917.ES.2015.20.49.30087.

25. Gadoev J, Asadov D, Tillashaykhov M, et al. Factors associated with unfavorable treatment outcomes in new and previously treated TB patients in Uzbekistan: a five year countrywide study. PLoS One. 2015;10(6):e0128907.

26. Lu H, Chen J, Wang W, et al. Efforts to reduce the disparity between permanent residents and temporary migrants: stop TB experiences in Shanghai. China Trop Med Int Health. 2015;20(8):1033-40.
27. Manissero D, Hollo V, Huitric E, et al. Analysis of tuberculosis treatment outcomes in the European Union and European Economic Area: efforts needed towards optimal case management and control. Euro Surveill. 2010;15(11):pii-19514.

28. Lonnroth K, Jaramillo E, Williams BG, et al. Drivers of tuberculosis epidemics: the role of risk factors and social determinants. Soc Sci Med. 2009;68(12):2240-6.

29. Konteh FH. Urban sanitation and health in the developing world: reminiscing the nineteenth century industrial nations. Health Place. 2009;15(1):69-78.

Received: 23-02-2016 Accepted: 18-04-2017 